\title{
Revolusi Mental melalui Penerapan Kebijakan Gerakan Magrib Mengaji di Kabupaten Lebak
}

\author{
Jumanah $^{\mathrm{a}, 1 \text { * }}$, Ujang Badrussalam ${ }^{\mathrm{b}, 2}$ \\ ${ }^{1,2}$ Sekolah Tinggi Ilmu Administrasi Banten, Indonesia \\ 1 Jumanah1011@gmail.com, 2 deratakamtsu@ gmail.com \\ * corresponding author
}

\section{ARTICLE INFO}

\section{Article history}

Received 2020-05-01

Revised 2020-06-05

Accepted 2020-06-22

Keywords

Mental revolution, magrib recitation movement policy

\begin{abstract}
Maghrib Mengaji Community Movement or better known as GEMMAR Mengaji is a national program of the Ministry of Religion of the Republic of Indonesia which is launched in every Province and Regency / City in Indonesia(Revelation, 2018). Indonesian Muslims constitute the majority community where almost all Indonesian citizens are predominantly Muslim. According to the 2010 statistical data, Muslims in Indonesia totaled 207,176,162 people or $87.18 \%$ followed by Christianity with a percentage of $6.96 \%$, in the next position, namely Catholicism with a percentage of $2.91 \%$, Hinduism 1.69\%, Buddhism. 0.72, and Khong hu chu $0.05 \%$. Today people prefer to spend their time watching television than reading the Koran or other positive activities(Kristiawan, 2016). This also happens in Lebak Regency as an area which also has the characteristics of the majority being Islam. So that with the implementation of the perda, the magrib reciting movement can bring about mental changes in thinking, especially among children and adolescents for a better life. The method used in this research is a qualitative method. The results in this study indicate that the implementation of the maghrib recitation regional regulation is quite good if viewed from the communication dimension which shows the socialization carried out by the implementing agency, resources in the form of incentive support for reciting teachers, adequate facilities in the implementation of magrib recitation, and the number of teachers. sufficient recitation.
\end{abstract}

\section{PENDAHULUAN}

Arus perkembangan zaman dan perkembangan media masa elektronik pada saat ini telah melahirkan pergeseran nilai, budaya, kultur, dan tradisi masyarakat, baik di perkotaan dan lebih-lebih di perdesaan. Dan akibatnya telah melahirkan perubahan sosial yang sangat signifikan di tengah-tengah masyarakat, imbasnya tradisi baik pada kelompok masyarakat pada saat ini telah tergerus oleh asupan budaya dan nilai-nilai yang berseberangan dengan kondisi dan tradisi masyarakat indonesia termasuk budaya maghrib mengaji.

Umat Islam Indonesia merupakan umat mayoritas yang dimana hampir semua warga negara Indonesia mayoritas beragama Islam. Menurut data statistik tahun 2010 umat Islam di Indonesia berjumlah 207.176.162 orang atau $87,18 \%$ di susul oleh agama Kristen dengan presentase $6,96 \%$, di posisi selanjutnya yaitu Katolik dengan presentase 2,91\%, Hindu 1,69\%, Budha 0,72, dan Khong hu chu $0,05 \%$. Dewasa ini orang-orang lebih senang menghabiskan waktunya untuk menonton televisi dibandingkan dengan membaca Alquran atau kegiatan lainnya yang positif. Hal ini bisa dilihat dengan sering munculnya mereka di media sebagai pelaku tindak asusila, kekerasan, tawuran, aborsi, konsumsi narkoba, dan perbuatan- perbuatan negatif lainnya selanjutnya. Berdasarkan data komnas perlindungan anak darin 2,5 juta kasus aborsi sebanyak 62,6\% dilakukan anak dibawah umur 18 tahun. BNN mencatat bahwa penggunaan narkoba termuda adalah anak usia tujuh tahun dan ada 8000 anak SD yang menjalani rehabilitasi narkoba. Prasetyo $(2012$, hlm. 12) padahal indonesia merupakan negara yang mayoritas Islam, kejadian- kejadian tersebut tidak lain karena sekarang umat Islam jauh akan agamanya jauh akan kitab sucinya (Sugestian, Syafei, \& Fakhruddin, 2018). 
Oleh Karena itu Revolusi mental salah satunya dimulai dari pendidikan, mengingat peran pendidikan sangat strategis dalam membentuk mental anak bangsa. Pengembangan kebudayaan maupun karakter bangsa diwujudkan melalui ranah pendidikan. Pembinaan karakter harus terus menerus dilakukan secara holistic. Revolusi mental sama pentingnya dengan pendidikan karakter yang harus segera dilakukan, meski sangat seder- hana, konsep yang ditawarkan Presiden Republik Indonesia Joko Widodo itu di- dasari oleh pemikiran yang sangat funda- mental, filosofis, dan empiris sehingga mampu menyentuh akar persoalan. Sejak masa kampanye sampai sidang kabinet pertama, Presiden sudah jelas menyata kan bahwa revolusi mental harus terjadi di Indonesia. Presiden Joko Widodo pernah menuliskan definisi revolusi mental sebagai "menciptakan paradigma, budaya politik, dan pendekatan nation building baru yang lebih manusiawi, sesuai dengan budaya Nusantara, bersa- haja, dan berkesinambungan." Dalam penjabarannya ada 3 (tiga) dimensi dalam pembangunan manusia Indonesia, yaitu sehat, cerdas, dan berkepribadian. Kesemuanya untuk menuju manusia Indonesia yang berkepribadian. (Kristiawan, 2016)

Pembentukan mental harus dilakukan secara holictis baik melalui pendidikan karakter namun perlu didukung oleh kehiatan religious dalam rangka pembinaan mental yang berakhlakuk kharimah dengan gerakan magrib mengaji. Dengan adanya kegiatan magrib mengaji adalah merupakan salah satu pembentukan mental spiritual warga dilakukan secara berbarengan. Dalam mensukseskan Gerakan Masyarakat Maghrib Mengaji, tokoh masyarakat mempunyai peran penting, antara lain sebagai berikut : (Fadjri Wahyu, 2018)

a) Menghimbau masyarakat untuk meramaikan Masjid di saat Maghrib secara khusus.

b) Membuat brosur yang isinya menyatakan untuk dapat kita melaksanakan shalat Maghrib dan mengaji di Masjid bersama-sama.

c) Memberikan ceramah kepada masyarakat melalui radio lokal untuk melaksanakan kegiatan Maghrib Mengaji.

d) Mensosialisasikan kepada masyarakat serta mengajak masyarakat untuk melaksanakan shalat di Masjid.

e) Mengevaluasi setiap Masjid yang ada, apakah mereka rutin melaksanakan Maghrib Mengaji.

f) Memberikan reward kepada Masjid / masyaarakat yang melaksanakan kegiatan thaharah Masjid.

g) Memberikan dukungan terhadap pengurus Masjid baik secara moril maupun materil untuk melaksanakan kegitan Maghrib Mengaji.

h) Mengadakan pertemuan dengan masyarakat serta dinas / instansi terkait untuk mendukung pelaksanaan kegiatan Maghrib mengaji.

i) Bekerja sama dengan perusahaan yang ada di Kecamatan Koto Tangah untuk berperan serta dalam pelaksanaan Maghrib Mengaji.

j) Memfasilitasi berkembangnya TPQ / MDA di lingkungan komplek/ kampong-kampung Mengaji.

Gerakan magrib yaitu suatu gerakan untuk membudayakan kegiatan membaca Al-Qur'an setelah shalat Magrib di kalangan masyarakat baik diperkotaan maupun pedesaan yang bertujuan untuk menghidupkan kembali budaya mengaji saat maghrib yang sebenarnya sudah mengakar jauh di Indonesia. Bahkan kenangan masa kecil kita pasti mengantarkan suasana setelah Maghrib adalah waktu khusus yang penuh barokah untuk belajar dan mengaji. Namun sayang kegiatan ini semakin lama semakin hilang dan ditinggalkan oleh masyarakat terutama anak-anak dan para remaja seiring dengan perkembangan zaman modern saat ini. Menyikapi hal ini tepatnya pada tanggal 30 Maret 2011 Bapak Menteri Agama Bapak Suryadharma Ali mencetuskan kembali kegiatan ini melalui program Pemerintah Gerakan Masyarakat Maghrib Mengaji. Oleh karena itu, beberapa wilayah salah satunya provinsi Riau telah menerapkan peraturan Gubernur Riau dan peraturan daerah Kabupaten Kampar (Bruno, 2019)

Begitupun halnya di Kabupaten Lebak telah menerbitkan Peraturan Bupati No. 4 tahun 2013 tentang gerakan magrib mengaji. Namun Berdasarkan observasi di lapangan ditemukan beberapa indikasi masalah : pertama, Perbup maghrib mengaji mengharuskan jam18:00 s/d 20:00 masyarakat wajib mengaji pada waktu maghrib, tetapi di lapangan tidak sepenuhnya demikian karna masih banyak masyarakat terutama para remaja yang masih nongkrong dan main di luar rumah pada waktu maghrib. Memudarnya budaya mengaji pada waktu maghrib, hal ini disebabkan karena dari dampak salah penggunaan teknologi,beberapa masyarakat masih banyak nonton TV pada waktu maghrib ,bermain 
Handphone di terotoar jalan pada waktu maghrib daripada mengaji. Kedua, Kurang tersedianya tenaga Pengajar/Ustadz dalam pengajaran mengaji,Sedangkan jumlah pemeluk agama Islam di Kabupaten Lebak khusunys daerah pusat pemerintahan sudah sangat banyak. Ketiga, Belum tersedianya tempat atau fasilitas mengaji yang cukup untuk aktivitas mengaji pada waktu maghrib. Keempat, Belum adanya sanksi yang tegas dari pihak yang berwenang, pada perbup nomor 4 Tahun 2013 tentang gerakan magrib sanksi berupa teguran saja, sehingga tidak menimbulkan efek jera terhadap masyarakat ynag tidak melaksanakan perbup tersebut. Oleh Karena itu Sat Pol PP Kabupaten Lebak sebagai Penegak Perbup tidak memiliki kekuatan untuk memberikan sanksi yang tegas. Kelima, Insentif guru mengaji yang belum terealisasi dengan merata, karena masih banyak guru mengaji yang belum mendapatkan insentif dikarnakan kurang adanya laporan-laporan daripihak Guru-guru Mengaji yang ada di wilayah Kecamatan Rangkasbitung kepada pihak yang memberikan insentif. Keenam, Kurang adanya sosialisasi dari Pemerintah Kabupaten Lebak. Berdasarkan permasalahan tersebut peneliti ingin mengetahui bagaimana pelaksanaan kebijakan gerakan magrib mengaji dalam mewujudkan revolusi mental?

\section{TINJAUAN PUSTAKA}

\section{Konsep Kebijakan Publik}

Kebijakan publik adalah apapun juga yang dipilih oleh pemerintah, apakah mengerjakan sesuatu itu atau tidak mengerjakan (mendiamkan) sesuatu itu (whatever government choose to do or not to do) (Nugroho, 2009 :86). Menurut Muhammad Ridha Suaib (2015) Mengemukakan: "Kebijakan Publik adalah sebuah kebijakan yang dikeluarkan pemerintah dalam rangka merumuskan artikulasi kepentingan seluruh skateholder dalam rangka menyelesaikan masalah dalam kehidupan berbangsa dan bernegara". Dalam tataran implementasi peneliti mengutip teori Teori George C. Edward Edward III (dalam Subarsono, 2011: 90-92) yang memiliki pandangan bahwa implementasi kebijakan dipengaruhi oleh empat variabel, yaitu:

1. Komunikasi, yaitu keberhasilan implementasi kebijakan mensyaratkan agar implementor mengetahui apa yang harus dilakukan, dimana yang menjadi tujuan dan sasaran kebijakan harus ditransmisikan kepada kelompok sasaran (target group), sehingga akan mengurangi distorsi implementasi.

2. Sumber daya, meskipun isi kebijakan telah dikomunikasikan secara jelas dan konsisten, tetapi apabila implementor kekurangan sumberdaya untuk melaksanakan, maka implementasi tidak akan berjalan efektif. Sumber daya tersebut dapat berwujud sumber daya manusia, misalnya kompetensi implementor dan sumber daya financial.

3. Disposisi, adalah watak dan karakteristik yang dimiliki oleh implementor, seperti komitmen, kejujuran, sifat demokratis. Apabila implementor memiliki disposisi yang baik, maka implementor tersebut dapat menjalankan kebijakan dengan baik seperti apa yang diinginkan oleh pembuat kebijakan. Ketika implementor memiliki sikap atau perspektif yang berbeda dengan pembuat kebijakan, maka proses implementasi kebijakan juga menjadi tidak efektif.

4. Struktur Birokrasi, Struktur organisasi yang bertugas mengimplementasikan kebijakan memiliki pengaruh yang signifikan terhadap implementasi kebijakan. Aspek dari struktur organisasi adalah Standard Operating Procedure (SOP) dan fragmentasi. Struktur organisasi yang terlalu panjang akan cenderung melemahkan pengawasan dan menimbulkan red-tape, yakni prosedur birokrasi yang rumit dan kompleks, yang menjadikan aktivitas organisasi tidak fleksibel.

\section{Konsep Gerakan Maghrib Mengaji}

Menurut Peraturan Bupati Lebak Nomor 4 Tahun 2013 Pasal 1 ayat (13) tentang Gerakan Gerakan magrib Mengaji adalah proses pengenalan huruf hijaiah sehingga mampu membaca al quran secara benar sesuai kaidah,yang dilaksanakan pada jam 18.00 sampai dengan jam 20.00 WIB. Adapun Tujuan gerakan magrib mengaji bertujuan untuk mempertahankan dan meningkatkan kebiasaan belajar pendidikan agama melalui proses pengkajian terhadap al qur'an oleh seluruh umat islam,pada sarana keagamaan yang telah ada,pada waktu jam 18.00 s/d 20.00 WIB. Jika dilihat berdasarkan konteks kebijakan ,melalui gerakan magrib mengaji yang di selenggarakan oleh masyarakat pada majlis-majis pengajian yang meliputi pondok pesantren ,majlis, surau, bale, sosompang, dibawah bimbingan 
kyai/ustadz/ustadzah.untuk mempertahan kan dan meningkat kan kebiasaan belajar pendidikan agama melalui proses pengkajian terhadap al qur'an. Fasilitas yang digunakan adalah Pondok pesantren,masjid,surau,bale,sosompang atau yang di sebut dengan nama lain yang di bimbing oleh kyai,ustaz/ustadzah,seorang alim atau guru agama islam.

Gerakan magrib mengaji dapat dilaksanakan ke dalam beberapa bentuk (Kartika \& Nurman, 2018) yaitu: (1) belajar membaca al-quran, (2) menghafal surat-surat pendek dan mengkhatamka al_quran, (3) belajar memahami arti kata dan terjemahan al-quran, (4) belajar memahami tafsr al-quran.

\section{METODE PENELITIAN}

Penelitian ini menggunakan jenis penelitian deskriptif kualitatif. Menurut Dencin dan Lincoln dalam moleong (2006:5) Mengemukakan: "Penelitian Kualitatif adalah penelitian yang menggunakan latar alamiah.Dengan maksud menafsirkan fenomena yang terjadi dan dilakukan dengan jalan melibatkan berbagai metode yang ada.Dengan berbagai karakteristik khas yang di miliki, Penelitian kualitatif memiliki keunikan tersendiri sehingga berbeda dengan penelitian kuantitatif". Jenis data yang digunakan adalah data primer dan data sekunder. Dalam menentukan informan pada penelitian ini, peneliti menggunakan teknik purposive sampling yaitu teknik pengambilan sampel yang hanya mengambil unit sampling yang sesuai dengan tujuan peneliti. Peneliti hanya memilih informan yang dianggap tahu dan dapat dipercaya mengetahui permasalahan yang terkait. Menurut sugiyono (2012:96) mengemukakan: "Purposive sampling adalah teknik penentuan sampel dengan pertimbangan tertentu..sampel ini lebih cocok digunakan untuk penelitian kualitatif. Misalnya orang tersebut yang dianggap paling tahu tentang apa yang kita harapkan, atau mungkin dia sebagai penguasa sehingga akan memudahkan penelitian menjelajahi obyek atau situasi sosial yang diteliti." Pihak-pihak yang emnjadi informan pihak pemerintah terdiri dari Bagian Hukum, Bagian Kesra, Polisi Pamong Praja, ustad dan ustadazh, tokoh remaja, para orang tua, dan kalangan remaja. Teknik pengumpulan data menggunakan observasi, wawancara, dokumentasi dan studi kepustakaan. Teori yang dipakai dalam penelitian ini sebagai pedoman wawancara adalah teori Edward III terdiri dari komunikais, sumber daya, disposisi dan birokrasi.

Validitas data yang digunakan adalah Triangulasi Teknik adalah penelitian menggunakan teknik pengumpulan data yang berbeda-beda untuk mendapatkan data dari sumber yang sama. Peneliti menggunakan observasi partisipatori, wawancara mendalam, dan dokumentasi untuk sumber data yang sama secara serempak. Triangulasi sumber berarti, untuk mendapatkan data dari sumber yang berbedabeda dengan teknik yang sama. Adapun analisis data yang digunakan adalah menurut Milles Huberman (Sugiyono:2008) melalui langkah-langkah: (1) Data Collection, (2) Data Display, (3) Data Reduction, (4) Conclusion drwawing.

\section{HASIL DAN PEMBAHASAN}

Gerakan Mengaji Al Qur'an diselenggarakan oleh masyarakat pada majelis-majelis pengajian yang meliputi Pondok Pesantren, Masjid, Surau, Bale, Sosompang di bawah bimbingan seorang Kyai/Ustadz/Ustadzah. Gerakan mengaji Al Qur'an bertujuan untuk mempertahankan dan meningkatkan kebiasaan belajar pendidikan agama melalui proses pengkajian terhadap Al Qur'an oleh seluruh umat Islam, pada sarana keagaman yang telah ada. Bagi peserta magrib mengaji kategori anakanak dari usia 5 tahun sampai dengan 15 tahun wajib mengikuti kegiatan mengaji Al Quran di Pondok Pesantren, Masjid, Surau, Bale, Sosompang atau yang disebut dengan nama lain yang dibimbing oleh Kyai, Ustad/Ustadzah, seorang alim atau guru agama Islam. Gerakan magrib mengaji dilaksanakan sejak pukul 18.00 sampai dengan pukul 20.00 WIB. Pemerintah Daerah wajib memberikan buku Lembar Kerja Peserta Magrib Mengaji kepada peserta magrib mengaji serta Pemerintah Daerah dapat memberikan sarana dan prasarana lain dalam rangka mendukung pelaksanaan Gerakan Magrib Mengaji dengan beban pembiayaan melalui Anggaran Pendapatan dan Belanja Daerah.

Berdasarkan penelitian yang penulis kemukakan pada bab sebelumnya bahwa gerakan magrib mengaji adalah suatu gerakan untuk membudayakan kegiatan mambaca al-qur'an setelah shalat magrib dari jam $18.00 \mathrm{~s} / \mathrm{d}$ jam 20.00. Di kalangan masyarakat yang betujuan untuk menghidupkan kembali budaya mengaji saat magrib yang sebenarnya sudah mengakar jauh di Indonesia bahkan kenangan masa 
kecil kita pasti kita menyatakan suasana setelah magrib adalah waktu khusus yang penuh barokah untuk belajar dan mengaji namun sayang kegiatan ini semakin lama semakin hilang dan ditinggalkan oleh masyarakat terutama anak-anak dan para remaja seiring peekembangan zaman modern ini. Dalam peraturan Bupati kab lebak nomor 04 tahun 2013 tentang gerakan magrib. Hasil observasi dan wawancara merupakan data primer dan penilitian ini kemudian data sekunder dari penelitian ini di peroleh dari dokumentasi dari berbagai sumber yang turut adil dalam peraturan Bupati ini meliputi:

a. Komunikasi sebagai berikut: salah satu keberhasilan dalam pelaksanaan suatu kebijakan ini adalah dengan komunikasi, komunikasi ini bertujuan untuk mengetahui pemahaman dan pengetahuan baik agen pelaksana maupun masyarakat terhadap keberadaan kebijakan ini. Adapun upaya yang dilakukan oleh pemerintah ini adalah dilakukannya sosialisasi dan pada pelaksanaanya dilakukan dengan baik, hal ini dapat dilihat dari upaya komunikasi yang sudah dilakukan melalui kegiatan sosialisasi yang dilakukan secara langsung melalui himbauan baik itu melalui media sosial yang ada di lingkunganKabupaten Lebak, namun tentu saja penerapan perda ini mengalami beberapa kendala yang dihadapi bagi sekelompok masyarakat yang secara geografis berada dipelosok yang tidak bisa mengakses informasi sosialisasi tersebut.

b. Sumber daya ; sumber daya ini meliputi adanya dukungan meliputi Insentif yang cukup untuk diberikan bagi agen pelaksana, insentif ini sudah mendapatkan perhatian dari pemerintah terutama untuk guru yang memberikan pengajaran tentang agama. Kemudian ketersediaan fasilitas turut memberikan dukungan meliputi buku panduan magrib, kemudian fasilitas mengaji. Selain itu jumlah guru mengaji yang tersebar diwilayah Kabupaten lebak cukup memadai guna terlaksana pprogran magrib mengaji.

c. Disposisi sebagai berikut: Respon cukup baik dari para aparatur pemerintah untuk mensukseskan pelaksanaan Implementasi Peraturan Bupati Nomor 4 tahun 2013 tentang Gerakan Magrib Mengaji dimana Peran guru-guru mengaji proaktif dalam pelaksanaan gerakan magrib mengaji.

d. Struktur birokrasi sebagai berikut: Proses dan mekanisme telah dilaksanakan dengan baik dari birokrasi terkait dengan pelaksanaan Implementasi . Peraturan Bupati Nomor 4 tahun 2013 tentang Gerakan Magrib Mengaji di Kabupaten Lebak.

\section{PENUTUP}

\section{Simpulan}

Penerapan Peraturan Bupati Nomor 4 tahun 2013 tentang Gerakan Magrib Mengaji di Kabupaten Lebak, peneliti menyatakan bahwa penelitian ini cukup berhasil dalam mewujudkan revolusi mental, penelitian sebagai berikut:

1. Komunikasi dapat dikatakan cukup baik. Hal ini dapat dilihat dari upaya komunikasi yang sudah dilakukan melalui kegiatan sosialisasi dilakukan baik secara langsung melalui media social ataupun melalui pemberitaan yang dilakukan oleh Radio RSPD Multatuli FM.

2. Kondisi pengajar magrib mengaji terbilang cukup untuk penunjang aktivitas gerakan magrib mengaji di kecamatan Rangkasbitung Kabupaten Lebak. Hanya kondisi fasilitas penunjang yang dimiliki setiap Mushola seperti alat tulis sangat minim.

3. Komitmen dan sikap pemerintah daerah melalui bagian kesejahteraan rakyat sebagai ketua pelaksana sudah cukup baik dengan berbagai cara untuk mensosialisasikan gerakan magrib mengaji namun ada sebagian masyarakat tidak mengetahui kegiatan magrib mengaji ini. Dukungan dari birokrasi yang terkait dengan pelaksanaan peraturan bupati nomor 4 tahun 2013 tentang gerakan magrib mengaji di kabupaten lebak telah dilaksanakan dengan baik. Hal ini dapat dilihat dari upaya persuasive kepada masyarakat

\section{Saran}

Berdasarkan hasil penelitian dan kesimpulan di atas, penulis memberikan saran-saran untuk mengsuseskan gerakan magrib mengaji ini yaitu: 
1. Selain dengan media sosial dan melalui radio gerakan magrib Mengaji ini perlu adanya sosialisasi lain dan tinjauan langsung seperti datang ke mesjid,mushola, untuk mengetahui apakah masyarakat kabupaten lebak sudah menjalankan "gerakan magrib Mengaji" atau tidak. Hal ini dikarenakan supaya dapat terwujud keseluruhan apa yang diharapkan pemerintah denan adanaya peaturan bupati tersebut.

2. Selain dari pihak pemerintah, masyarakat diharapkan juga kesadarannya dalam membaca Al-quran setelah salat Magrib.

3. Perlu adanya media lain selain seperti reklame, supaya "Gerakan magrib Mengaji" dapat berjalan dengan lebih baik lagi. Pemerintah Daerah harus menambahkan jumlah sarana dan prasarana untuk menunjang kegiatan pada rencana anggaran tahun berikutnya.

\section{DAFTAR PUSTAKA}

\section{Sumber Buku:}

Agustino, Leo, 2014. Dasar-Dasar Kebijakan Publik, Bandung: Alfabeta.

Abdul Wahab, Solichin. 2002. Analisis Kebijaksanaan dari formulasi ke Implementasi Kebijaksanaan Negara. Jakarta: Bumi Aksara.

Ahmadi, Rulam. 2016. Metodologi Penelitian Kualitatif. Yogyakarta: Ar-RUZZ MEDIA

A G Subarsono, 2015. Analisis Kebijakan Publik Konsep, Teori dan Aplikasi. Yogyakarta: Pustaka Pelajar.

Dwiyanto, Indiahono. 2009. Kebijakan Publik Berbasis Dynamic Policy Analysis. Yogyakarta: Gava Media.

Herman, P. N. (2018). Evaluasi Pelaksanaan Kebijakan Peraturan Daerah Indragiri Hulu Nomor 3 Tahun 2014 Tentang Perlindungan Anak (Studi Kasus Maghrib Mengaji Kebijakan Kota Layak Anak Di Desa Air Molek Ii Kecamatan Pasir Penyu Kabupaten Indragiri Hulu). Publika, 4(2), 299-318.

Kurniawan, Luthfi J dan Mustafa Lutfi. 2012. Perihal Negara, Hukum dan Kebijakan Publik, Setara Press, Malang.

Muchlis Hamidi, 2017. Kebijakan Publik: Proses, analisis partisipasi Copyright@Muchlis Hamidi.

Muhammad Ridha Suaib. (2015). Pengantar Kebijakan Publik. Yogyakarta: Calpulis.

Moleong, J.Lexy, 2006. Metodologi Penelitian Kualitatif, Bandung: PT. Remaja Rosdakarya.

Sahya Anggara, 2014. Kebijakan public, CV Pustaka Setia:2018.

Sugiyono, 2012. Memahami Penelitian Kualitatif, Bandung : CV. Alfabeta.

Sugiyono. 2009. Metode Penelitian Kuantitatif,Kualitatif dan R\&D. Bandung: Alfabeta

\section{Sumber Jurnal:}

Kartika, R., \& Nurman, N. (2018). Pelaksanaan Gerakan Masyarakat Magrib Mengaji Di Nagari Lubuk Basung Kabupaten Agam. Journal of Civic Education, 1(2), 141-148. https://doi.org/10.24036/jce.v1i2.185

Kristiawan, M. (2016). Telaah Revolusi Mental Dan Pendidikan Karakter Dalam Pembentukkan Sumber Daya Manusia Indonesia Yang Pandai Dan Berakhlak Mulia. Ta'dib, 18(1), 13. https://doi.org/10.31958/jt.v18i1.274

Sugestian, G., Syafei, M., \& Fakhruddin, A. (2018). Pembinaan Keagamaan Masyarakat Kota Bandung Melalui Program Magrib Mengaji: Studi Kasus Pada Masjid Al-Fithroh Kecamatan Bandung Kulon. TARBAWY: Indonesian Journal of Islamic Education, 4(2), 191. https://doi.org/10.17509/t.v4i2.8563 
Wahyu, F. (2018). Pengembangan Masyarakat Islam: Program Magrib Mengaji Kecamatan Koto Tangah Padang, Sumatera Barat Fadjri Wahyu. Jurnal Al_Fuad, 1(2), 115-125.

\section{Sumber Peraturan:}

Peraturan Daerah Nomor 17 Tahun 2006 Tentang Penyelenggaraam Ketertiban, Kebersihan, dan Keindahan. 